\title{
Family Learning Resources on Science Language Development of Elementary Students*
}

\author{
Shin-Feng Chen \\ National Pingtung University, Pingtung, Taiwan
}

\begin{abstract}
Science language includes specific science vocabulary, semantics, and syntax, which plays an important role in the reading comprehension of science language. Besides, parental social economic status is another important factor which influences the reading comprehension of science language. Parental social economic status, parental jobs, parental educational levels, parental income, and the learning environment of the family have close relationships. Therefore, the purposes of this study were to explore the factors influencing elementary students' science language ability by using Mplus 6.0 and Statistical Package for Social Science (SPSS) 18 to construct the structure equation model and to explore how much the elementary school students' parental educational levels affected the children's science language. The samples were 1,048 4th and 6th graders from Kaohsiung City and Pin-Tung Country. There were two questions: One was that how much the elementary school students' parental educational levels affected the children's science language, and the other was that how much the family learning resource affected the students' science language. The results showed that there was cause-effect relationship (Chi-Square $=7.559, d f=6$, and $p=0.272$ ) and good model fit indicators. It showed that the parental educational levels and the family learning resources would directly affect the elementary students' achievements of science language.
\end{abstract}

Keywords: science language development, parental education level, family resources, structural equation modeling (SEM), reading comprehension, oral comprehension

\section{Introduction}

Science language plays an important role in the reading comprehension of science texts. It is different from the language used in everyday life, because the language of science typically conveys theories or methods not thought to be used in daily life. Halliday (1993) once said that the basic component of science language was scientific jargon. Without an understanding of science language, a systematic knowledge of science would be difficult to achieve. Science language includes specific terms, semantic structures, and syntax. Aside from its grammatical structure and vocabulary, the science language is important in the learning of scientific knowledge (Fang, 2006; Yang \& Chen, 2008).

There are multiple factors which affect the usage of science language when learning scientific knowledge. According to McCormick and Zutell (2011), these factors include physical, genetic, emotional, sociological,

\footnotetext{
*Acknowledgement: The author is appreciative of the financial support in the form of research grants awarded to Dr. Shin-Feng Chen from the National Science Council, Republic of China under Grant Nos. NSC 100-2511-S-153-007, NSC 103-2420-H-153-001-MY2, and MOST 103-2410-H-153-001-MY2.

Shin-Feng Chen, Ph.D., associate professor, Department of Education, National Pingtung University.
} 
educational, cognitive, language, and reading processing variances, while there are unbreakable relationship between science language and science textbook reading comprehension. Therefore, among these factors, family socioeconomic status is considered the most important, because it is deeply correlated with parents' occupational prestige, education level, and family income (Hwang, 2000). Many research studies have reported that family social economical status (SES). SES variables include parental occupation, parental education level, and family income, and are considered to have a positive impact on the "cultural capital" of their children (Hwang, 2000). Thus, the size of a family's SES affects the educational resources which can help their child's learning and in turn facilitates the child's educational development (Chen, 1998; Hsieh, 2003; Hwang, 1998). The research questions are as follow: First, how much does parents' educational level affect the science language ability of elementary school children? Second, how much does family learning resource (including math learning resource and science learning resource) affect the science language ability of elementary school children?

The main purpose of the present research is to exam the factors which influence the science language of elementary students by building and testing a structure equation modeling (SEM) using Mplus 6 and Statistical Package for Social Science (SPSS) 18. Variables used in this study include parents' educational level, family's financial resources used on education, and the impact of these resources on science language achievement. A concept model of science language for fourth and fifth grade students from two southern cities in Taiwan assessed in this study was created and then tested by means of model fit analysis. The purpose of this analysis was to determine if this model fit the assessed data gathered from these students.

\section{Methods}

This study aims to examine the factors which influence the science language of elementary students by building and testing a structure equation modeling. The following statement will be based on the participants, research variables, hypothetical initial factor model, and analysis.

\section{Participants}

This study examined how the oral and reading comprehension of 4th and 6th grade students were impacted by their parents' education level and the financial resources their parents used on the students' education.

The assessed population of this study included fourth and sixth graders $(N=1,048)$ from schools in three areas in southern Taiwan: (1) Kaohsiung County, which included townships outside of Kaohsiung City; (2) Kaohsiung City; and (3) Pingtung County in southern Taiwan. Schools taking part in this study were public supported. Table 1 shows the total number of Grade 4 and Grade 6 students, classes, and schools in Taiwan during 2007 and 2008.

Table 1

Total Grades, Students, Classes, and Schools in Taiwan in 2007 and 2008

\begin{tabular}{lllllll}
\hline Area & Grade 4 & Grade 6 & Students & Classes & Schools & Percent (\%) \\
\hline Pingtung County & 10,828 & 12,216 & 23,044 & 878 & 166 & 40.49 \\
Kaohsiung County & 14,802 & 16,214 & 31,016 & 1,072 & 152 & 37.07 \\
Kaohsiung City & 18,343 & 20,486 & 38,829 & 1,247 & 92 & 22.44 \\
Total & 43,973 & 48,916 & 92,889 & 3,197 & 410 & \\
\hline
\end{tabular}

Note. Estimated average number of students was calculated as 29 (= students total/class total) (Retrieved from http://www.edu.tw). 
A three-stage stratified sampling design was implemented on these data. The sampling design for each stage was as the follows: Stage 1 stratified schools according to the manifest variable of the target population. There were sample lists for each school, and the sampling procedure for what was performed separately. The probability of the school being chosen was determined by the measure of size (MOS) and was estimated by probability proportional to school size. Stage 2 was randomly selecting classes from schools stratified in Stage 1. In Stage 3, all students in the randomly selected classes were identified as the population sample used in this study. Therefore, this population included eight schools, 16 classes, and 273 students from Pingtung County; seven schools, 14 classes, and 370 students from Kaohsiung County; five schools, 10 classes, and 273 students from Kaohsiung City. Thus, the total sample was 1,048 students from a ratio of 8:7:5 schools which reflected the target population.

\section{Research Variables}

Research variables included in this study were one survey questionnaire from Database of Elementary School Children's Development in Science and the Oral Comprehension and Reading Comprehension of Science Language for Children in Elementary School (Wang et al., 2011; 2012). Independent variables included parents' education level and family's expended financial resources on education, which were measured by an item on the students' survey questionnaire, and the online oral and reading comprehension test scores.

Parental education level. In the survey questionnaire from Database of Elementary School Children's Development in Science, items 9 and 10 assessed the parents' education level. These items evaluated the highest education level achieved by each parent. Options included "No formal education at all," "An incomplete grade for a elementary school course," "Elementary school graduate," "Junior high school graduate," "Senior high school or vocational high school graduate," "5-year junior college program graduate", "2-year college program graduate," "University graduate," "A Master's degree or higher," and "Unknown." Except for the option "unknown," higher scores represented better education level and vice versa. The internal reliability coefficient of items was 0.830 .

Family education resources. Data for the families learning resources came from the Database of Elementary School Children's Development in Science. These data included learning mathematics and science by way of software, videos, reference books, collateral readings (e.g., journals or comic books), and objects for learning (e.g., building blocks, microscopes, plants, and pets). Higher scores on these variables represented expending more learning resources on mathematics and science. The internal reliability coefficient of items was 0.830 .

Science language ability. The oral comprehension of science language ability was composed by an online test of Oral Comprehension of Science Language (OCSL) for Children in Elementary School. This test included 18 items, each with four possible test answer options. The context of test is mainly about basic science literacy, including three main topics: (1) to identify the question; (2) to collect data and provide proof according to the question; and (3) to make explanations according to the proof they found. The score was estimated from the expected a posteriori (EAP) value by the three parameter logistic (3PL) model of Item Response Theory. The coefficient Alpha to internal reliability coefficient for items on the oral comprehension test is 0.621 ; test-retest reliability is 0.680 ; and the criterion-related validity coeffection is 0.50 calculating with the Children Oral Comprehension Test by Lin and Chi (2000). 
The test of reading comprehension of science language was conducted online and assessed by using the Reading Comprehension of Science Language (RCST) for Children in Elementary School. RCST included four components: (1) analysis reasoning; (2) comparison reasoning; (3) interpretation; and (4) evaluation. RCST included 25 items, each with four possible test answer options. The score was estimated from the EAP value by the 3PL model using Item Response Theory. The internal reliability coefficient for items on the reading comprehension online test is 0.74 . The test-retest correlations reveled that the test is stable at 0.72 . This evidence supported the requirement of internal consistency and stability of test reliability.

Table 2

Summary of Variables, Factor Loading, and Descriptive Statistic Measures

\begin{tabular}{|c|c|c|c|c|c|c|}
\hline $\mathrm{OV}$ & Survey question item & $F L$ & $M$ & $S D$ & Skew & Kurtosis \\
\hline PEL & A1-Mother's education level & 0.79 & 2.10 & 0.69 & -0.13 & -0.93 \\
\hline$\xi_{1}$ & A2-Father's education level & 0.76 & 2.14 & 0.75 & -0.24 & -1.17 \\
\hline FER & B1-Math learning resources & 0.79 & 1.36 & 1.08 & 0.17 & -1.25 \\
\hline$\xi_{2}$ & B2-Science learning resources & 0.76 & 1.97 & 1.25 & 0.09 & -1.01 \\
\hline SLA & $\mathrm{C} 1$ - Oral comprehension of science language & 0.68 & 0.33 & 1.06 & -0.21 & -0.19 \\
\hline$\eta_{1}$ & $\mathrm{C} 2$ - Reading comprehension of science language & 0.61 & 0.04 & 0.58 & 0.30 & -0.54 \\
\hline
\end{tabular}

Note. $\mathrm{OV}=$ observed variable; $\mathrm{PEL}=$ parents' education level; FLR = family's learning resources; SLA = online comprehension science language ability scores; and FL = factor loading.

Table 2 shows the smallest value of skew is 0.09 and its largest value is 0.30 . The smallest value of kurtosis is 0.19 and its largest value is 0.19 . All of values did not violate the assumption of normal distribution (Kline, 2011).

\section{Hypothetical Initial Factor Model}

Figure 1 is the hypothetical initial factor model of the present research. There are four main independent variables: (1) mother's education level; (2) father's education level; (3) mathematics learning resources; and (4) science learning resources. This analysis also made use of two dependent variables: (1) oral comprehension of science language; and (2) reading comprehension of science language. The researcher investigated this model by using a SEM of science language and a corresponding causal model.

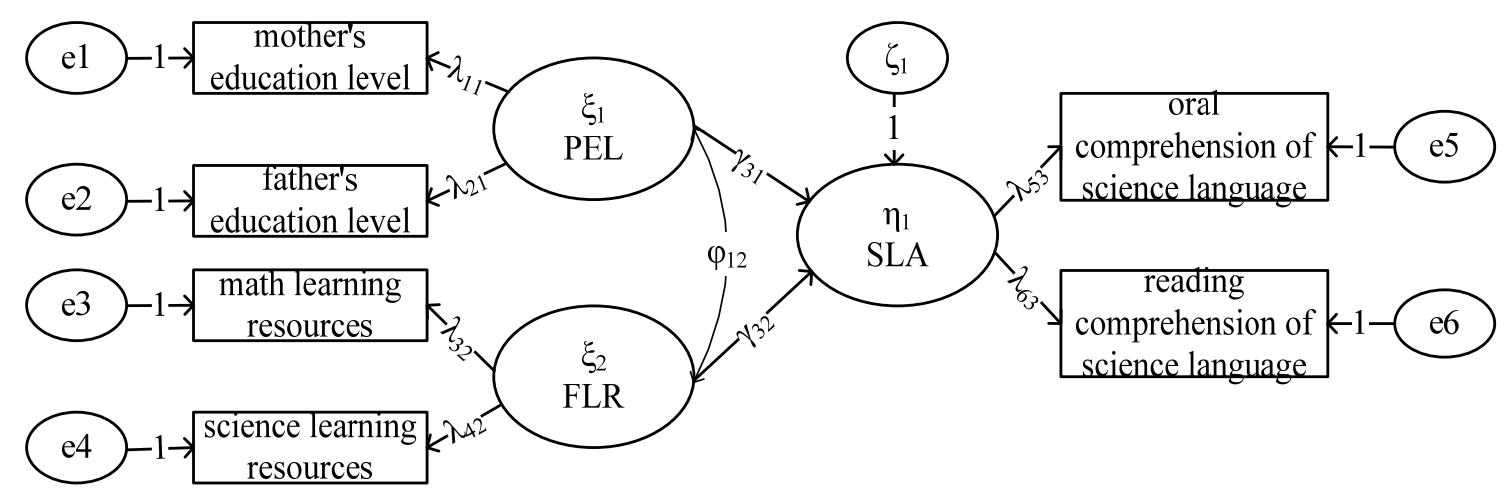

Figure 1. Hypothetical initial factor model.

\section{Analysis}

SEM is a statistical method to process cause-target mode, and it can do path analysis, factor analysis, regression analysis, and analysis of variance. SEM is a statistical methodoly connecting theory mode and real 
data. The first step of defining the theory and concept can be specific theory and concepts, and can also be from experience and literature review. But these theory and concept must have hypothesis and deductive process to make verify the mode (Cherng, Chen, \& Chen, 2011).

Table 3 shows a covariance matrix of the six observed variable used in the present research model: A1 represents mother's education level; A2 represents father's education level; B1 represents mathematics learning resources; B2 represents science learning resources; $\mathrm{C} 1$ represents oral comprehension of science language score; and $\mathrm{C} 2$ represents reading comprehension of science language score. This covariance matrix was used to run an estimation of the parameters of the SEM and to test the goodness of fit by means of Mplus 6.0.

Table 3

Covariance Matrix of Data

\begin{tabular}{lllllll}
\hline & $\mathrm{A} 1$ & $\mathrm{~A} 2$ & $\mathrm{~B} 1$ & $\mathrm{~B} 2$ & $\mathrm{C} 1$ & $\mathrm{C} 2$ \\
\hline $\mathrm{A} 1$ & 0.48 & & & & & \\
$\mathrm{~A} 2$ & 0.31 & 0.56 & & & & \\
$\mathrm{~B} 1$ & 0.14 & 0.17 & 1.17 & & & \\
$\mathrm{~B} 2$ & 0.21 & 0.24 & 0.82 & 1.57 & 0.13 & 0.34 \\
$\mathrm{C} 1$ & 0.15 & 0.20 & 0.12 & 0.25 & 0.25 & \\
$\mathrm{C} 2$ & 0.06 & 0.09 & 0.06 & 0.10 & & \\
\hline
\end{tabular}

\section{Results}

The following statement will be based on the model estimation, including original parameter estimation and structural regression of model's parameters.

The estimations of the original variables of the developed model are shown in Table 4. The factor loading was between 0.47 and 0.83 . The error variances were all positive and significant. Therefore, the result of the estimation fit the standard recommended by SEM scholars (Kline, 2011).

Table 4

Original Parameter Estimation

\begin{tabular}{llll}
\hline OV & $F L$ & $S E$ & $t$ \\
\hline A1 & 0.83 & 0.070 & 11.866 \\
A2 & 1.00 & - & - \\
B1 & 0.65 & 0.071 & 9.136 \\
B2 & 1.00 & - & - \\
C2 & 0.47 & 0.061 & 7.745 \\
C1 & 1.00 & - & - \\
\hline
\end{tabular}

Note. $\mathrm{OV}=$ observed variable; and $F L=$ factor loading.

SEM was applied to the present research as a main statistical technique. SEM is a statistical technique for testing and estimating models of causal relations and can also be used for other analyses, such as path analysis, factor analysis, regression analysis, or analysis of variance (ANOVA) (Cherng et al., 2011). By fitting the observed empirical data to the theoretical model, SEM can be used for theory testing (Chen, 2014; Kline, 2011). The main purpose of using SEM in this study was to test the theory model fit by absolute fit measures, relative fit indices, and Parsimonious fit measures. The goodness of fit indices results were as follows: Chi-Square equals to 0.559 ( $d f=6, p=0.272)$, GFI $=0.998, \mathrm{AGFI}=0.992, \mathrm{NFI}=0.994, \mathrm{CFI}=0.999, \mathrm{RMSEA}=0.016$, and $\mathrm{CN}=2,329$. All remaining goodness of fit indices also demonstrated an acceptable fit. 


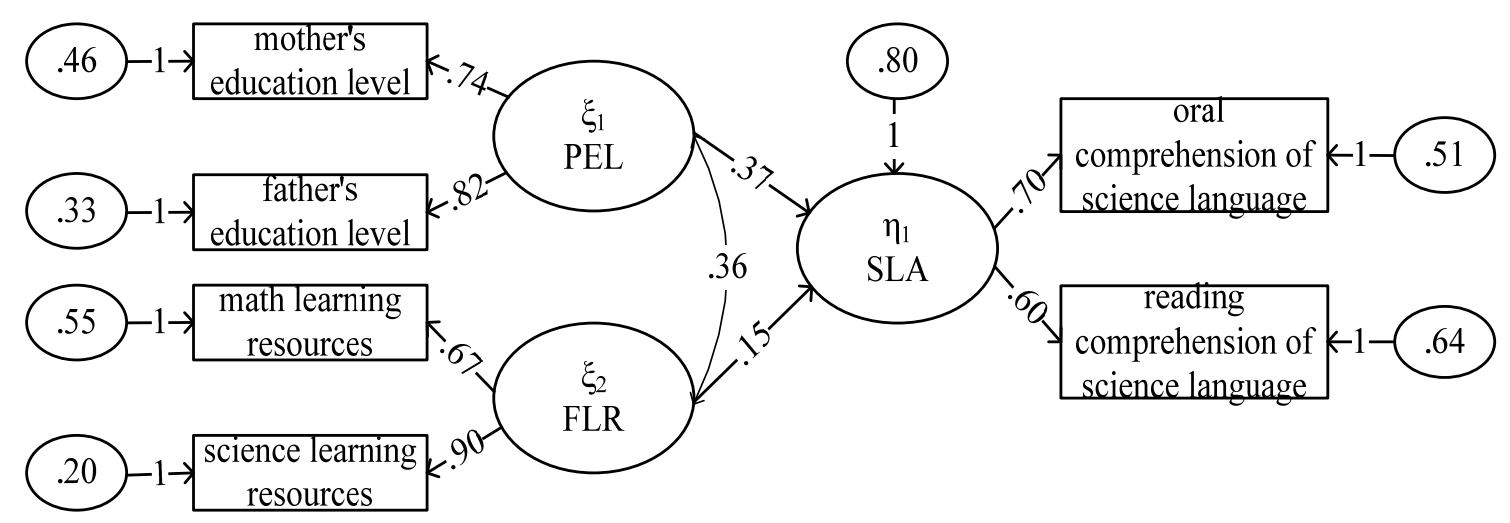

Chi-Square $=7.559(\mathrm{df}=6, \mathrm{p}=.272)$

GFI $=.998, \mathrm{NFI}=.994, \mathrm{RMSEA}=.016, \mathrm{CN}=2329$

Figure 2. Structural regression of model.

From the standardized effect size of the latent variables of the factors among science language, parental education level, and family learning resources in Figure 2, the effect of paternal education level on science language was greater than family learning resources, and both had positive and significant effect on science language. The total effect sizes were 0.37 and 0.15 which indicated the higher the parents' education level and mathematics or science learning resources, the more positive effect would result on children's performance on oral or reading comprehension of science language.

\section{Discussion and Conclusions}

The purpose of the present research was to investigate the effect of parental education level and family learning resources to the development of science language. Samples were drawn by the probability proportionate to size (PPS) sampling technique from students in Grades 4 and 6 from Kaohsiung County, Kaohsiung City, and Pingtung County. Results indicated that parents' education level and family learning resources on mathematics and science learning were strongly related to the development of science language achievement among students in Grades 4 and 6. Analyses of model fit to the data revealed an overall model fit of the causal model was accepted (Chi-Square $=7.559, d f=6$, and $p=0.272$ ). All indices demonstrated good model fit. These results of model fit supported the above conclusion.

Thus, the more learning resources a family could provide, the higher a child's performance could be seen in science language reading comprehension. This result agrees with previous research results (Chen, 1998; Hwang \& Yang, 2006), which support the conclusion that families with higher socioeconomic level have more resources and greater potential to benefit the achievement of their children. Parents' social economic status also plays an important role in students' science language learning. The data in this research shows that parents' educational level influences students' science language learning greatly. The result is the same as the researchers exploring academic achievement impact factors before (Christensen et al., 2014; Korat, 2011). In conclusion, the assist learning for elementary disadvantage family students is urgent, because only in this way can we upper disadvantage students' competitiveness.

In this study, the impact of the parent's level of education was more important than the family's learning resources on a child's science language achievement. Thus, the direct influence from the parents toward their children was far more important than the learning resources that they could provide. 


\section{References}

Chen, C. C. (1998). A model of ethnic and family background influence on children's academic achievement—A comparison between aboriginal and non-aboriginal students in Taitung. Journal of Education and Psychology, 21(1), 85-106.

Chen, S. F. (2014). Structural equation modeling: The application of Mplus. Tapiei, Taiwan: The Psychological Publishing Co..

Cherng, B. L., Chen, C. C., \& Chen, S. F. (2011). Structure equational modeling. In C. C. Chen, B. L. Cherng, S. F. Chen, \& T. C. Liu (Eds.), Multivariate analysis. Taipei, Taiwan: The Wunan Publishing Co..

Christensen, D., Zubrick, S. R., Lawrence, D., Mitrou, F., \& Taylor, C. L. (2014). Risk factors for low receptive vocabulary abilities in the preschool and early school years in the longitudinal study of Australian children. PLoS ONE, 9(7), 1-19.

Fang, Z. (2006). The language demand of science reading in middle school. International Journal of Science Education, 28(5), 491-520.

Halliday, M. A. K. (1993). The analysis of scientific texts in English and Chinese. In M. A. K. Halliday \& J. R. Martin (Eds.), Writing science: Literacy and discursive power (p. 304). Washington, D.C.: Falmer Press, Taylor \& Francis Inc..

Hsieh, M. Y. (2003). A study of the relationship between parental socioeconomic backgrounds and students' academic achievements. Bulletin of Educational Research, 49(2), 255-287.

Hwang, F. M. (1998). The investigation of social class on the difference of control structure and resource distribution in family education. Journal of Culture and Society, 6, 43-73.

Hwang, F. M., \& Yang, S. A. (2006). A study of the inference of family factors on primary school student's environment behavior. Journal of Taiwan Normal University: Education, 51(1), 159-183.

Hwang, Y. J. (2000). The mechanism of status attainment in Taiwan: A structural analysis of covariance. Soochow Journal of Sociology, 5, 213-248.

Lin, B. G., \& Chi, P. H. (2000). The development of the test of language comprehension. Bulletin of Special Education, 19, $105-125$.

Kline, R. B. (2011). Principles and practice of structural equation modeling. New York, N.Y.: The Guilforad Press.

Korat, O. (2011). Mothers' and teachers' estimations of first graders' literacy level and their relation to the children's actual performance in different SES groups. Education and Treatment of Children, 34(3), 347-371.

McCormick, S., \& Zutell, J. (2011). Instructing students who have literacy problems (6th ed.). Boston, M.A.: Allyn \& Bacon.

Wang, J. R., Chen, S. F., Tsay, R. F., Chou, C. T., Lin, S. W., \& Kao, H. L. (2011). Development of an instrument for assessing elementary school students' written expression in science. The Asia-Pacific Education Researcher, 20(2), 276-290.

Wang, J. R., Chen, S. F., Tsay, R. F., Chou, C. T., Lin, S. W., \& Kao, H. L. (2012). Developing a test for assessing elementary students' comprehension of science texts. International Journal of Science and Mathematics Education, 10(4), 955-973.

Yang, W. G., \& Chen, S. W. (2008). A comparison of the discourses of science texts in English and Mandarin on Newton's First Law of Motion. Journal of National Taiwan Normal University: Mathematics \& Science Education, 53(1), 113-137. 